Katarina Marinčič

UDK 821.133.1.09 Gautier T.:37.091.3

Filozofska fakulteta Univerze v Ljubljani

kmarincic@gmail.com

\title{
OD NAJPOMEMBNEJŠIH K NAJBOLJ ILUSTRATIVNIM AVTORJEM: THÉOPHILE GAUTIER KOT IZHODIŠČE ZA POUK O FRANCOSKI ROMANTIČNI KNJIŽEVNOSTI
}

\section{KAKO UČITI KNJIŽEVNOST V DOBI INTERNETA?}

Gornje vprašanje ni ne ne retorično ne pesimistično, češ, kako splob še učiti. Nasprotno: izhaja iz prakse in je zastavljeno z vsaj zmernim optimizmom.

Od kod optimizem? Pred dvajsetimi leti, ko sem avtorica pričujočih vrstic začela s poučevanjem francoske književnosti, so bili študentje še (lahko) hvaležni za fotokopije iz tujih knjig in revij, pa celo za na tablo napisan seznam glavnih del Victorja Hugoja. Preden smo se dogovorili za obvezno čtivo, smo se pri knjižničarki previdno pozanimali o zalogah. Eden od ključnih razlogov, da smo nekoč v drugem letniku brali roman Adolphe Benjamina Constanta, je bilo osupljivo število izvodov v oddelčni knjižnici. Morda je naključje dobro izbralo - a vendarle je izbiralo naključje.

Dejstvo, da danes ni več tako, nas po mojem globokem prepričanju ne bi smelo skrbeti, temveč nasprotno. Če ima žalovanje za knjigo kot predmetom iz papirja in kartona morda še kak smisel, kadar gre za čisto zasebne bralne navade in $\mathrm{z}$ njimi povezane obrede starejših in srednjih generacij, pa ni v šolskem in univerzitetnem okolju za nostalgijo po papirnati knjigi prav nobenega razloga. Dejstvo, da je večino francoske klasike in kar nekaj sekundarne literature o njej mogoče povsem legalno prebrati na internetu, lahko moti kvečjemu lene profesorje. Lenih študentov niti ne: ti se v časovni stiski radi zatečejo vsaj k wikipediji. Ne eni ne drugi, ne leni profesorji ne leni študentje, pa si ne zaslužijo, da bi nam bili za merilo.

Če skušam ista opažanja povzeti nekoliko resneje: v dvajsetih letih, odkar poučujem francosko književnost, so se materialne okoliščine bistveno spremenile. Od pomanjkanja virov smo prišli do stopnje, ko je virov toliko, da se iskalec med njimi včasih tudi izgubi. Zgodi se denimo - primer je pretiran, a ni izmišljen - da študent, ki je „črpal snov“ z interneta, na izpitno polo zapiše, da je Charlemagne pevec s Haitija. To nas sicer lahko razjezi ali nasmeje, ne more pa služiti kot resen argument zoper rabo interneta. Nasprotno: profesor, ki mu je wikipedija odvzela breme naštevanja najpomembnejših pisateljev in njihovih glavnih del, si lahko v odpravljanju tovrstnih težav s časovno in prostorsko orientacijo najde novo poslanstvo. 


\section{SINTEZA, S POMOČJO KATERE LAŽJE NAJDEMO POT DO POSAMEZNOSTI}

Če smo nekoč, oboroženi s kredo, fotokopijami in prosojnicami, začeli pri posameznih podatkih, ki smo jih nato bolj ali manj uspešno sestavili v celoto, je danes, vsaj pri poučevanju predmeta, kot je literarna zgodovina, najbrž pametneje začeti z druge strani, pri celoti. Pri tem seveda ne gre za ambicijo, do kraja izčrpati neko tematiko, in še manj za površnost, hitri prelet ali ptičjo perspektivo. Celota, ki jo lahko ponudi učitelj, je še zmeraj samo izsek. Za učenca bi morala biti uporabna predvsem kot vzorec, kot metoda, navsezadnje tudi kot model iskanja po internetu.

Naj to ponazorim s primerom iz pedagoške prakse.

Romantično gibanje v Franciji je bilo, kot ugotavljajo številni literarni zgodovinarji, v veliki meri uvoženo, razvijalo se je pod tujimi, zlasti nemškimi in angleškimi vplivi, obenem pa je bilo une affaire de génération (Millet: 8), torej projekt celotne generacije ali celo dveh generacij francoskih pisateljev, pesnikov, slikarjev in glasbenikov. Med najpomembnejšimi člani kroga, ki se je oblikoval okrog znamenitega romantičnega pesnika Victorja Hugoja, tako denimo najdemo slikarja Eugèna Delacroixa, ki je na Hugojevo poezijo bržkone vplival globlje od pesniških sodobnikov; in obratno, Hugojeva poezija je, zlasti z orientalsko tematiko, navdihovala Delacroixovo slikarstvo; Delacroix je ilustriral razkošno izdajo Goethejevega Fausta v prevodu Gérarda de Nervala, Nervalov prevod je navdihnil Berlioza - in tako naprej.

Poučevanje „po starem“ nas tu prisili k analitičnemu pristopu, k obravnavi posameznih tem in avtorjev. S tem ni v osnovi prav nič narobe, tako so študirale številne generacije pred nami - težave se utegnejo začeti, ko pride do neskladja med metodo, ki jo profesor uporablja $\mathrm{v}$ predavalnici, in študentovim individualnim načinom dela. Dokler snov obravnavamo po strogo ločenih segmentih, se ne smemo posebej čuditi, če so vsaj manj prizadevni študentje zadovoljni že s prvim zadetkom, ki ga navrže internetni brskalnik.

\section{OD VÉLIKIH K MANJŠIM AVTORJEM}

Spoznanje, da so t.i. mali avtorji pomemben del literarne zgodovine, nikakor ni novo. Pa vendar: tradicionalni način poučevanja od učitelja zahteva upoštevanje določene hierarhije. Če izhajamo iz posameznosti, je najbrž skoraj nujno začeti z najpomembnejšimi; če predvidevamo, da učenec nima dostopa do osnovnih informacij, smo mu jih dolžni posredovati. $V$ nasprotnem primeru bomo morda ubrali drugačen pristop in skušali poleg najpomembnejših avtorjev, deloma pa celo namesto njih, obravnavati najznačilnejše, take, ki nam lahko služijo kot izhodišče za celostni pogled na svojo dobo.

Pri iskanju značilnih avtorjev ne gre za poskus prevrednotenja njihove vloge $\mathrm{v}$ literarni zgodovini. Seveda so takšna prevrednotenja razmeroma pogost pojav. $\mathrm{Z}$ današnjega stališča se denimo Nerval, ki je v svojem času veljal za sopotnika 
romantičnega gibanja, marsikateremu literarnemu zgodovinarju utegne zdeti pomembnejši, vplivnejši avtor od uradnega začetnika francoske romantike Lamartina. Pa vendar: da bi avtorja prepoznali kot značilnega, ilustrativnega predstavnika neke dobe, ga zato ni treba prestaviti na višje mesto v literarnem kanonu.

\section{THÉOPHILE GAUTIER}

Nasprotno. Ob primeru, kot je Théophile Gautier (1811-1872), bomo literarnozgodovinski pomen morda celo nekoliko zanemarili na račun ilustrativnosti. Avtorja, ki mu je Charles Baudelaire posvetil zbirko Rože zla ter mu v posvetilu dodelil naziva poète impeccable in parfait magicien ès lettres françaises (Baudelaire: 2), najbrž ne moremo kar tako uvrstiti med minores. A če je opus nesporno vélikega Victorja Hugoja že s kvantitativnega stališča težko obvladljiv, lahko v relativno manj pomembnem delu Théophila Gautiera najdemo številne orientacijske točke, ki nam navsezadnje pomagajo razumeti tudi estetski razvoj (še) pomembnejših pesnikov, med njimi Hugoja in Baudelaira.

\section{ROMANTIČNI UMETNIK}

Kaj nam torej „ilustrira“ Théophile Gautier? Začnemo lahko kar z že navedeno ugotovitvijo, da je romantično gibanje v Franciji podvig celotne generacije umetnikov, ki jih bolj kot zakonitosti posameznih umetnosti (literatura, likovna umetnost, glasba) povezujejo in zavezujejo splošnejša estetska pravila. Idealni romantični umetnik bi bil pravzaprav vse troje hkrati: pesnik, slikar in glasbenik. Victor Hugo, ob robu svoje literature (včasih dobesedno na robovih rokopisov) izvrsten risar in akvarelist, se je temu idealu približal za pol koraka. Gautier, šolan slikar, pesnik, pisatelj, literarni in likovni kritik ter libretist se mu je približal bistveno bolj. Njegov znameniti opis bitke za Hernanija (la bataille d'Hernani; spopad med pristaši nove, romantične šole in klasicisti na ob premieri Hugojeve drame Hernani na odru Comédie française 1. 1830) v polnosti poznazarja zavezništvo med romantičnimi umetniki različnih smeri:

On ne pouvait cependant pas, quelque brave qu'il fût, laisser Hernani se débattre tout seul contre un parterre mal disposé et tumultueux, contre des loges plus calmes en apparence mais non moins dangereuses dans leur bostilité polie, et dont le ricanement bourdonne si importun au-dessous du sifflet plus franc, du moins, dans son attaque. La jeunesse romantique pleine d'ardeur et fanatisée par la préface de Cromwell, résolue à soutenir " l'épervier de la montagne ", comme dit Alarcôn du Tisserand de Ségovie, s'offrit au maître qui l'accepta. Sans doute tant de fougue et de passion étaient à craindre, mais la timidité n'était pas le défaut de l'époque. On s'enrégimenta par petites escouades dont chaque homme avait pour passe le carré de papier rouge timbré de la griffe Hierro. Tous ces détails sont connus, et il n'est pas besoin d'y insister.

On s'est plu à représenter dans les petits journaux et les polémiques du temps ces jeunes hommes, tous de bonne famille, instruits, bien élevés, fous d'art et de poésie, ceux-ci 
écrivains, ceux-là peintres, les uns musiciens, les autres sculpteurs ou architectes, quelques-uns critiques et occupés à un titre quelconque de choses littéraires, comme un ramassis de truands sordides. Ce n'étaient pas les Huns d'Attila qui campaient devant le ThéâtreFrançais, malpropres, farouches, hérissés, stupides; mais bien les chevaliers de l'avenir, les champions de l'idée, Les défenseurs de l'art libre; et ils étaient beaux, libres et jeunes. Oui, ils avaient des cheveux - on ne peut naitre avec des perruques - et ils en avaient beaucoup qui retombaient en boucles souples et brillantes, car ils étaient bien peignés. Quelques-uns portaient de fines moustaches, et quelques autres des barbes entières. Cela est vrai, mais cela seyait fort bien à leurs têtes spirituelles, hardies et fières, que les maîtres de la Renaissance eussent aimé à prendre pour modèles (Gautier 2011: 87-88).

\section{L'ART POUR L'ART}

Isto besedilo pa pravzaprav priča tudi o medgeneracijskem zavezništvu, ki se je le malo pozneje končalo. Prva generacija romantikov je svoje poslanstvo vselej videla tudi (ali celo pretežno) v družbenem angažmaju: Après comme avant 1830, les poètes ont maintenu intacte l'idée de leur mission comme accompagnateurs et guides spirituels de l'humanité moderne (Bénichou: 12).

Mlajša generacija, ki ji je pripadal Gautier, s političnimi razmerami svojega časa sicer ni bila zadovoljna, a je na družbo gledala $\mathrm{z}$ ironične distance, pogosto celo $\mathrm{z}$ zaničevanjem. Politično udejstvovanje umetnikov ter $z$ njim povezano uporabo umetnosti v propagandne namene so romantiki druge generacije doživljali kot zanikanje bistva umetnosti. Takole Gautier v uvodu k romanu Madmoiselle Manpin (1835):

Il y a deux sortes d'utilité, et le sens de ce vocable n'est jamais que relatif. Ce qui est utile pour l'un ne l'est pas pour l'autre. Vous êtes savetier, je suis poète. - Il est utile pour moi que mon premier vers rime avec mon second. - Un dictionnaire de rimes m'est d'une grande utilité; vous n'en avez que faire pour carreler une vieille paire de bottes, et il est juste de dire qu'un tranchet ne me servirait pas à grand-chose pour faire une ode. - Après cela, vous objecterez qu'un savetier est bien au-dessus d'un poète, et que l'on se passe mieux de l'un que de l'autre. Sans prétendre rabaisser l'illustre profession de savetier, que j'bonore à l'égal de la profession de monarque constitutionnel, j'avouerai bumblement que j'aimerais mieux avoir mon soulier décousu que mon vers mal rimé, et que je me passerais plus volontiers de bottes que de poèmes. Ne sortant presque jamais et marchant plus habilement par la tête que par les pieds, j'use moins de chaussures qu'un républicain vertueux qui ne fait que courir d'un ministère à l'autre pour se faire jeter quelque place. Jesaisqu'ilyenaquipréferentlesmoulinsauxéglises, etlepainducorpsàceluidel'âme. Aceux-là, jen'ai rien à leur dire. Ils méritent d'être économistes dans ce monde, et aussi dansl'autre. /.../ Rien de ce qui est beau n'est indispensable à la vie. - On supprimerait les fleurs, le monde $n^{\prime} e n$ souffrirait pas matériellement; qui voudrait cependant qu'il n'y eût plus de fleurs? Je renoncerais plutôt aux pommes de terre qu'aux roses, et je crois qu'il n'y a qu'un utilitaire au monde capable d'arracher une plate-bande de tulipes pour y planter des choux.

A quoi sert la beauté des femmes? Pourvu qu'une femme soit médicalement bien conformée, en état de faire des enfants, elle sera toujours assez bonne pour des économistes (Gautier 1966: 44-45). 


\section{VRNITEV H KLASICIZMU, NAPOVED SIMBOLIZMA}

Potem ko se je v ideoloških vprašanjih razšel s starejšo generacijo romantikov, se je Gautier od romantičnega gibanja odvrnil tudi v estetskem pogledu. Primerjava z Goethejem je zagotovo pretirana, pa vendarle: tako kot je Goethe, v mladosti Rousseaujev častilec, v poznejši Hugojevi izpeljavi romantične estetike videl enega od argumentov za vrnitev h klasičnim vzorom, tako naj bi Gautier ob slogovnih ekscesih poznih in zapoznelih romantikov začutil, da je čas za „reakcijo“: njegova zbirka Emajli in kameje (Émaux et camées, 1852) pomeni vrnitev od lamartinovske izpovednosti k deskriptivni, oblikovno izbrušeni poeziji 17. ter zlasti 18. stoletja. Hkrati - ta dvojnost je pomenljiva in $z$ didaktičnega stališča zelo ilustrativna - je Gautier z omenjeno zbirko močno vplival ne le na skupino Parnasovcev, temveč tudi na literarnozgodovinsko bistveno pomembnejše simboliste.

\section{TUJI VPLIVI}

Gautierova vpetost v literarno zgodovino pa ima poleg časovne tudi prostorsko dimenzijo. Gautier je v svojem imenu vselej odkrito priznaval tisto, kar imajo avtorji francoskih literarnozgodovinskih priročnikov še danes navado sramežljivo, včasih skorajda s slabo vestjo pospraviti pod poglavje Les influences étrangères. Kot solibretist znamenitega baleta Giselle se je denimo za navdih zahvalil Heinrichu Heineju, kot avtor fantastičnih zgodb je vselej priznaval svoj dolg E.T.A. Hoffmannu, pa tudi (vsaj v Franciji bistveno manj znanemu) Achimu von Arnimu. Za razliko od sodobnikov, ki so o tujih vplivih večinoma razmišljali v smeri vprašanja: „Da ali ne - in če da, v kolikšni meri?" jasnjeval, ne da bi se do nje vrednostno opredeljeval. Hoffmannovska fantastika, je ugotavljal, je Francozom blizu zaradi svoje realistične komponente, čista fantastika (le fantastique pur) Achima von Arnima jim je s svojo mistično-religiozno komponento razmeroma tuja.

La cause de la rapidité du succès d'Hoffmann est assurément là où personne ne l'aurait été chercher. - Elle est dans le sentiment vif et vrai de la nature qui éclate à un si haut degré dans ses compositions les moins explicables.

Hoffmann, en effet, est un des écrivains les plus habiles à saisir la physionomie des choses et à donner les apparences de la réalité aux créations les plus invraisemblables. Peintre, poète et musicien, il saisit tout sous un triple aspect, les sons, les couleurs et les sentiments. Il se rend compte des formes extérieures avec une netteté et une précision admirables. Son crayon est vif et chand; il a l'esprit de la silhonette et découpe en se jouant mille profils mystérieux et singuliers dont il est impossible de ne pas se souvenir, et qu'il vous semble avoir connu quelque part.

Sa manière de procéder est très logique, et il ne chemine pas au hasard dans les espaces imaginaires, comme l'on pourrait le croire (Gautier 1904: 43-44).

1 Tak odnos zasledimo že pri francoskih razsvetljencih in predromantikih. Ne le Voltaire, celo Mme de Staël, v svojem času glavna posrednica med nemško in francosko kulturo, Francoze svari pred nepremišljenim posnemanjem tujih vzorov, npr. Shakespeara in Goetheja: La pièce de Faust cependant n' est certes pas un bon modèle. Soit qu'elle puisse être considérée comme l'oeuvre du délire de l'esprit ou de la satiété de la raison, il est à désirer que de telles productions ne se renouvellent pas /.../ (Staël: 367). 


\section{POSMRTNO ŽIVLJENJE ROMANTIKE}

Théophile Gautier je torej z odmikom od romantičnega gibanja naznanil, vsaj deloma tudi povzročil zaton romantike $v$ Franciji. Njegov primer je, kot smo skušali pokazati, za ponazoritev tega literarnozgodovinskega dejstva še posebej uporaben, saj nam omogoča pogled iz več zornih kotov. S pomočjo njegove literature pa lahko osvetlimo še en zanimiv pojav. Osrednji, doktrinarni, v takem ali drugačnem smislu angažirani ${ }^{2}$ del francoske romantične književnosti danes obstaja predvsem kot literarnozgodovinsko dejstvo. En del pa je vendarle preživel tudi v drugačnem pomenu besede. Ugotovitev je provizorična in kot taka povsem nestrokovna. A kratek pogled na seznam francoskih književnih besedil prve polovice 19. stoletja, ki danes, četudi v obliki risank ${ }^{3}$, še vedno pritegnejo množice, nas utegne navesti na misel, da je ostala popularna tista književnost romantične dobe, ki je to bila že v svojem času: slikoviti zgodovinsko-pustolovski romani Alexandra Dumasa starejšega, Notre Dame de Paris Victorja Hugoja, Hugojevi Nesrečniki... Théophile Gautier se ni seveda nikdar povzpel do superzvezdniškega statusa prvega ali veličine drugega. Pa vendar je ta estet, larpurlartist in elitist $1.1857 \mathrm{v}$ podlistku, leto pozneje pa še v knjižni obliki objavil Mumïin roman (Le roman de la momie), po katerem je 1. 2000 nastal (sicer ne prav odmeven) musical ${ }^{4}$. Film po tej napeti ljubezensko-arheološko-avanturistični zgodbi je nastal že daljnega leta $1911^{5}$.

\section{BIBLIOGRAFIJA}

BAUDELAIRE, Charles (1964) Les Fleurs du mal. Paris: Garnier-Flammarion. BÉNICHOU, Paul (1988) Les mages romantiques. Paris: Gallimard.

GAUTIER, Théophile (1904) Souvenirs de théatre, d'art et de critique. Paris: Charpentier

GAUTIER, Théophile (1966) Mademoiselle de Maupin. Paris: Garnier-Flammarion. GAUTIER, Théophile (2011) Histoire du romantisme. Paris: Éditions du Félin.

MARINČIČ, Katarina (2010) Un roman pour la génération dot.com?: Le comte de Monte-Cristo dans 1'adaptation de Stephen Fry: Acta Neophilologica 2010, 135-143.

MILLET, Claude (ed.) (1994) L'Esthétique romantique en France. Paris: Pocket. STAËL, Germaine de (1968) De l'Allemagne. Paris: Garnier-Flammarion.

\footnotetext{
2 Tudi angažma zoper udejstvovanje je seveda oblika angažmaja, kot se jasno pokaže v navedenem odlomku iz uvoda h Gospodični Maupin. Besedilo je mlajša generacija romantikov dojela kot programsko.

3 Prav ta, pogojno rečeno trivialni del romantične književnosti, je deležen predelav, ki pričajo o živosti: ne le spoštljivo kostumskih filmskih in televizijskih adaptacij, temveč tudi variacij in prestavitev v naš čas. Omenimo le številne knjižne predelave Grofa Monte Crista (cf. Marinčič 2010).

4 Avtorja Catherine Jacob in Olivier Gavignaud.

5 Scenarij Théo Bergerat, realizacija Albert Capellani, Henri Desfontaines.
} 


\section{POVZETEK}

Od najpomembnejših k najbolj ilustrativnim avtorjem: Théophile Gautier kot izhodišče za pouk o francoski romantični književnosti

Članek naniza nekaj predlogov za poučevanje književnosti in literarne zgodovine v obdobju interneta. Opozarja na dejstvo, da v dobi, ko primarni in sekundarni viri postajajo iz dneva v dan dostopnejši, učitelj v veliki meri izgublja vlogo posredovalca gradiv in osnovnih podatkov. Po drugi strani pa ga obilica informacij postavlja pred novo nalogo: učencu oziroma študentu mora pomagati pri časovni orientaciji in iskanju bistvenega. $\mathrm{V}$ tem kontekstu se zdi smiselno, da poleg avtorjev, ki sodijo v literarni kanon, pri pouku literarne zgodovine obravnavamo tudi (relativno) manj pomembne, a ilustrativne avtorje (kot primer iz francoske literarne zgodovine navajamo Théophila Gautiera).

Ključne besede: didaktika književnosti, francoska romantika, značilni avtorji, Théophile Gautier

\section{ABSTRACT}

\section{From the Literary Canon to Illustrative Authors: the Case of Théophile Gautier}

The article discusses some new approaches to teaching literature and literary history in the digital age. In an era when access to primary as well as to secondary literature is no longer an exclusive privilege, the teacher, free of the obligation to provide essential information, should instead provide the students with means of orientation. In this aim, typical, illustrative texts of (relatively) minor authors (such as Théophile Gautier) should be read and discussed in class besides the works belonging to the literary canon.

Key words: didactics of literature, French romanticism, illustrative authors, Théophile Gautier 